\title{
LA JURISDICCIÓN DE LOS DERECHOS: LEGISLADOR Y JUEZ A LA LUZ DEL CONCEPTO CLÁSICO DE DETERMINATIO
}

\author{
ABOUT JURISDICTION OF RIGHTS: LEGISLATOR AND JUDGE IN \\ THE LIGHT OF THE CLASSIC CONCEPT OF DETERMINATIO
}

\section{Luis Alejandro Silva IrarráZaval ${ }^{*}$}

\begin{abstract}
RESUMEN: El artículo tiene por objeto rescatar la importancia del concepto clásico de determinatio para contener la fuerza expansiva de la garantía judicial de los derechos fundamentales. La naturaleza de estos derechos exige un juicio prudencial que determine primariamente su alcance práctico, esto es, lo que generalmente mandan, prohíben o permiten. Este juicio prudencial se corresponde mejor con un razonamiento político (determinatio legislativa) que un razonamiento jurídico (determinatio judicial), porque la determinación primaria del contenido de los derechos fundamentales depende más de un discurso de la razón natural que de la razón artificial, propia de los operadores técnico-jurídicos. En consecuencia, sería el legislador a través de la norma positiva, el responsable de fijar primariamente los límites de los derechos fundamentales, y tocaría al juez sujetarse a dichos límites. Al arrogarse los jueces autoridad para proteger los derechos al margen o en contra de la ley, abandonan el tipo de razonamiento que es característico de la prudencia judicial (prudentia iuris), por uno que es propio de la prudencia política (prudentia legis).
\end{abstract}

Palabras clave: Derechos fundamentales; determinatio; separación de los poderes.

ABSTRACT: This paper retrieves the importance of the classic concept of determinatio, as a key to restraining the expansive force of fundamental rights when judicially enforced. The very same nature of fundamental rights requires a prudential judgment so as to determine their legal scope, that is what they generally command, permit or prohibit. Such prudential judgement belongs to the political authority in the exercise of its legislative function, because it corresponds better with a discourse grounded on natural reasoning than with the artificial reasoning which is proper to the legal discourse. Thus, when the Judiciary protects fundamental rights at the expenses of the legal order, either ignoring or contradicting statutory law, he practices a kind of reasoning that is not judicial in nature but political.

Keywords: Fundamental rights; determinatio; separation of powers.

\footnotetext{
* Doctor en Derecho de la Universidad de los Andes, Chile. Profesor de la Facultad de Derecho de la Universidad de los Andes, Chile. Código Orcid 0000-0003-3404-7707. Dirección postal: Mons. Álvaro del Portillo 12.455, Las Condes, Santiago-Chile. Dirección electrónica: 1silva@uandes.cl. Este artículo se enmarca en el Proyecto Fondecyt Regular No 1161334. Debo agradecer al profesor de la Universidad de Navarra, Fernando Simón Yarza, por sus valiosas aportaciones al trabajo, que ayudaron decisivamente a ampliar su alcance y su base bibliográfica.
} 


\section{INTRODUCCIÓN}

¿Por qué el juez habría de garantizar los derechos fundamentales según las directrices fijadas por el legislador en la ley? En una época en que los derechos fundamentales son percibidos precisamente como una defensa contra el poder, los jueces disfrutan -quizá como nunca antes- de libertad para determinar el contenido de los derechos fundamentales al margen de o contra la ley ${ }^{1}$. El objetivo de este artículo es desarrollar un argumento para acotar esa libertad del juez, demostrando que la determinación del contenido de los derechos fundamentales es una función de naturaleza política -que no judicial-y que, por lo tanto, el legislador es más idóneo que el juez para realizarla.

Hoy en día, es un lugar común en las sociedades occidentales afirmar que los derechos humanos constituyen el fundamento de la legitimidad de nuestros ordenamientos. Grandes juristas y iusfilósofos han proclamado, a lo largo de las últimas décadas, que vivimos en "la era de los derechos" y hablamos "la lengua de los derechos"3. Un hito en la internacionalización de este discurso fue marcado por la Declaración Universal de los Derechos Humanos, aprobada por la Asamblea General de las Naciones Unidas hace sesenta años. Merced a la Declaración, el catálogo de derechos humanos ha venido a erigirse en el lugar axiológico central de un número creciente de ordenamientos. Consecuentemente, los principios jurídicos superiores, sobre cuyas bases habría de asentarse el resto del Derecho, se han concentrado en las exigencias del individuo frente al poder público ${ }^{4}$.

Intensificado muy por encima de lo que los redactores de la Declaración pudieron prever, el tinte individualista que el discurso de los derechos ha cobrado en las últimas décadas ha dado lugar a argumentadas críticas ${ }^{5}$. Con todo, ello no nos impide insistir en que una interpretación cabal de los mismos permite identificarlos con principios éticos universales, esto es, con principios de ley natural o de razón práctica ${ }^{6}$. Este hecho lleva consigo algunas implicaciones para la teoría y la práctica constitucionales que, desgraciadamente, tienden a ser ignoradas por muchos juristas.

Se halla extendida, desde luego, una vaga convicción de que existe un "ámbito político" en lo que respecta a la implementación de los derechos, al margen del cual deben permanecer los jueces. Este convencimiento, sin embargo, apenas es articulado con claridad y precisión, y en tantas ocasiones está movido por meros intereses políticos ligados al resultado de un caso concreto más que por una reflexión teórica. Aunque los constitucionalistas

\footnotetext{
1 Entre las causas de este fenómeno debe anotarse la transformación del concepto de Constitución, como la describe FAVOREAU (2001).

2 Henkin (1990); Bobbio (1990).

3 García de Enterría (2009).

${ }^{4}$ Este resultado se explica, al menos en parte, como reacción a las concepciones colectivistas. Como afirmó durante el mismo proceso de elaboración de la Declaración Universal, uno de sus principales redactores, el profesor libanés Charles H. Malik, "el riesgo más profundo de la época" venía planteado por el colectivismo, el cual exige "la extinción de la persona humana como tal, en su misma individualidad e inviolabilidad últimas". GLENDON (2001) p. 39.

5 Glendon (1991).

6 Para una exposición más amplia sobre el concepto clásico de ley natural como razón práctica, RHONHEIMER (2011); en especial las pp. 261 y ss. También Simón (2017a) pp. 29-50.
} 
perciben la existencia de una confusión de tareas judiciales y legislativas, es difícil definir con claridad dónde reside y cuáles son sus causas. Este trabajo aspira a contribuir -aunque sea parcialmente- al esclarecimiento de ella, desarrollando el contenido de un concepto de filosofía política conocido como determinatio legislativa. Se trata, en definitiva, de comprender mejor cuál es la institución más idónea para cumplir la función de determinar primariamente el significado de los derechos fundamentales, si el juez o el legislador.

El artículo se estructura en tres partes, además de la Introducción y la Conclusión. En la primera de ellas, Los derechos humanos como "higher law", hemos procurado fijar el lugar que ocupan los derechos humanos en el razonamiento práctico sobre la justicia, amparándonos tanto en la historia de la Declaración Universal de Derechos Humanos como en la tradición occidental clásica del pensamiento ético. La conclusión a la que llegamos es que se identifican con los primeros principios de la razón práctica, esto es, con los bienes humanos básicos, evidentes en sí mismos, que dan forma a la realización humana y determinan el comportamiento de cualquier agente racional. A partir de ahí, la sección siguiente -El derecho positivo como determinatio de los derechos humanos- explica cómo todo el derecho positivo constituiría una implementación o determinatio de estos bienes básicos. Este proceso de determinatio no tiene ni debe tener, a nuestro juicio, un carácter técnicojudicial. No ha de basarse propiamente en la razón artificial del Derecho, que es propia de los operadores jurídicos (y de los jueces, particularmente), sino que debe estar guiado por la prudencia política. La determinatio de los derechos humanos no ha de sobredimensionar, además, ningún interés particular concreto, sino que debe ser guiada por el bien común, del que dependen los derechos humanos de toda la colectividad. La tercera sección busca responder la pregunta ¿A quién corresponde la determinatio?, y desarrolla un argumento para justificar que la tarea de precisar el contenido de los derechos fundamentales primariamente, se aviene mejor con la función legislativa que con la judicial, de la que derivaría una cierta preeminencia del legislador sobre el juez.

\section{LOS DERECHOS HUMANOS COMO HIGHER LAW}

La necesidad de precisar el contenido de los derechos fundamentales, ya sea para un caso en particular, ya para la generalidad de los casos, es una premisa de este trabajo. Esta necesidad respondería a la naturaleza de los mismos, los cuales, en cuanto bienes humanos básicos, admiten una variedad amplísima de concreciones según las circunstancias. Así pues, para justificar la necesidad de una determinatio de los derechos fundamentales, así como para defender una relativa preeminencia de la determinatio legislativa por sobre la judicial, es preciso decir algo acerca de los derechos fundamentales en el marco del razonamiento práctico sobre la justicia. Este es el propósito de la presente sección.

A lo largo de la historia, la idea de un higher law, de una "ley natural" a la que debe someterse el entero orden jurídico-positivo, ha cobrado expresión en numerosas civilizaciones a través de conceptos diversos. En un conocido ensayo, C. S. Lewis englobaba todas estas categorías de culturas y tradiciones milenarias de diversos puntos del planeta (physei dikaion, lex naturae, Tao, dharma, etc.) bajo la simple etiqueta de "doctrina de la objetivi- 
dad del valor"7. Lewis alertaba en su ensayo sobre la penetración del subjetivismo moral en los estratos medios de la cultura; entre las élites jurídicas, sin embargo, la reivindicación de la objetividad de los valores había decaído ya con el positivismo jurídico de la segunda mitad del siglo XIX y la primera del XX.

Tras la Segunda Guerra Mundial, no obstante, la idea de unos valores objetivos resurgió encarnándose en la doctrina contemporánea de los derechos humanos. Heredera de la moderna teoría de los derechos naturales -formulada principalmente por John Locke y explícitamente preconizada por los principales textos constitucionales revolucionarios ${ }^{8}$-, también la Declaración Universal de los Derechos Humanos se apoyó en la mencionada "objetividad del valor". Más aún, la Declaración fue expresamente objeto de una discusión filosófica fundamental en la UNESCO que puso de manifiesto la común percepción, en diferentes culturas, de los derechos como valores básicos objetivos. Creado en 1947 por la UNESCO con el propósito de reflexionar sobre los fundamentos de la Declaración que se estaba gestando en el seno de la Comisión de Derechos Humanos, el Comité sobre las Bases Teóricas de los Derechos Humanos envío un cuestionario a grandes pensadores de las distintas tradiciones filosóficas y religiosas del planeta para que pudiesen exponer su punto de vista acerca de una Declaración universal de derechos, cuestionario que dio lugar a un informe de enorme interés.

Entre los aspectos que conviene destacar del informe, llama la atención la disposición de intelectuales provenientes de tradiciones no occidentales a acoger el discurso de los derechos humanos. En efecto, varios encuestados señalaban que, aunque tal discurso hubiese sido forjado en Occidente, en sus propias tradiciones se reconocían, de un modo u otro, los fundamentos para afirmar un catálogo de derechos. Desde la tradición china, por ejemplo, se explicó que, en el confucionismo, el "cumplimiento del propio deber para con el prójimo, más que la reivindicación de derechos”, constituye el concepto ético básico. Ello no impediría, sin embargo, reconocer en la tradición confucionista una "actitud favorable respecto a los demás hombres en cuanto que tienen las mismas aspiraciones, y por lo tanto los mismos derechos" . Algo parecido ocurre con las tradiciones budista e hinduista. Aun-

\footnotetext{
LEWIS (2001) p. 18.

8 En la doctrina lockeana, el fin de la autoridad pública es la protección de los derechos naturales del hombre (LOCKE $(1690) \$ 137$, p. 78). Sin perjuicio de sus orígenes más remotos, el énfasis en los derechos naturales más que en la propia ley natural objetiva es típicamente moderno y, de acuerdo con autores como STRAUSS (1953) p. 165, encuentra en Locke su mayor exponente en la génesis del Constitucionalismo. En el Constitucionalismo americano, la doctrina de los derechos naturales del hombre encuentra una expresión inequívoca, por ejemplo, en las "self-evident truths" reconocidas por la Declaración de Independencia, así como en las convicciones ampliamente compartidas por los Founding Fathers. De hecho, uno de los argumentos que se esgrimieron inicialmente para no reconocer un catálogo de derechos fue, precisamente, el de evitar restringir -en virtud del principio: inclusio unius est exclusio alterius - el alcance de los derechos naturales (The Federalist Papers, $₫$ 84). Posteriormente, esta dificultad sería solventada con una referencia, en la IX Enmienda, a la vigencia de los derechos no expresamente reconocidos (non-enumerated rights). Acerca del iusnaturalismo que subyace al Constitucionalismo norteamericano, CoRWIN (1928) pp. 149-185. La misma convicción iusnaturalista se encuentra, por lo demás, en la Declaración de los Derechos del Hombre y del Ciudadano (1789), cuyo artículo 2, por ejemplo, afirma expresamente que "el fin de toda asociación política es la conservación de los derechos naturales e imprescriptibles del hombre".

9 Chung-Shun Lo (1948) p. 187.
} 
que no encontremos en ellas una teoría equivalente a la doctrina occidental de los derechos naturales, tanto Buda como Manu afirmaron la existencia de libertades y virtudes esenciales para una vida digna, y propusieron -según explicaba el politólogo S. V. Puntambekar en sus respuestas al cuestionario- un código de diez libertades y virtudes fundamentales ${ }^{10}$. Como ha enfatizado Mary Ann Glendon, "los resultados de la encuesta de la UNESCO fueron muy alentadores: indicaban que los principios subyacentes al borrador de la Declaración estaban presentes en muchas tradiciones culturales y religiosas, aunque no siempre expresados en términos de derechos" 11 . Y es que, como ha señalado John Finnis, el discurso de los derechos humanos "constituye un simple modo de esbozar los perfiles del bien común, de los diversos aspectos del bienestar individual en la comunidad"12.

La universalidad del consenso alcanzado en torno a los derechos humanos pone de manifiesto, en el fondo, el carácter básico de los principios que estaban en juego. Conforme a la tradición aristotélico-tomista, los primeros principios universales de la ley moral natural son evidentes en sí mismos y se corresponden con los bienes objeto de las inclinaciones básicas del ser humano ${ }^{13}$. En la medida en que los derechos humanos se identifican con esos bienes, esenciales para la realización humana, pueden considerarse como principios fundamentales de la ley natural. No es de extrañar, pues, que su reconocimiento sea anterior a la reflexión sobre su propia justificación teórica, como se desprende de una conocida anécdota narrada por Jacques Maritain. Activo miembro del "comité de filósofos" de la UNESCO, el pensador francés explicaba que, ante el asombro de cierto visitante a un meeting de la Comisión de Derechos Humanos por el acuerdo al que llegaban personas de procedencias tan diversas, los vocales replicaron: "Sí, estamos de acuerdo sobre los derechos, pero a condición de que nadie nos pregunte por qué" ${ }^{14}$.

En relación con el propósito de este artículo, lo recién señalado tiene una doble implicación en la que es preciso reparar:

En primer lugar, si los derechos humanos stricto sensu -esto es, abstracción hecha de las reglas concretas, normalmente procesales, que suelen incorporar los catálogos de derechos- recogen bienes objeto de inclinaciones humanas básicas -vida, sociabilidad humana, salud, intimidad, conocimiento, religión, etc.-, todo el derecho positivo está llamado a realizarlos. Sucede entonces que, en sus implementaciones concretas, los derechos humanos lo impregnan prácticamente todo, o lo que es lo mismo, son prácticamente todo en el ordenamiento jurídico.

Al mismo tiempo, sin embargo, los derechos humanos no dan ninguna indicación concreta acerca de las exigencias particulares en que se traducen. Si el ordenamiento entero es implementación de los derechos humanos, y si las prohibiciones universales y absolutas que estos puedan trazar, válidas semper et ad semper, no pasan de ser un extremo insignificante, sucede entonces que, en su consideración puramente abstracta, los derechos huma-

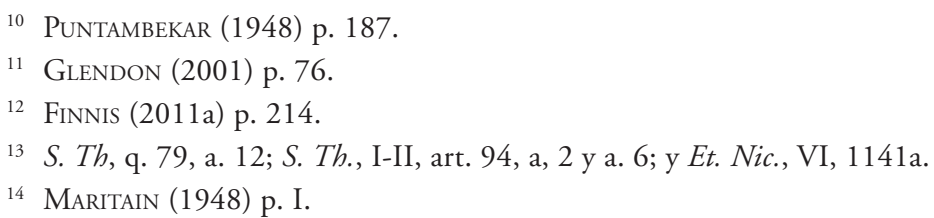


nos no permiten concluir prácticamente nada, o lo que es lo mismo, no son prácticamente nada en el ordenamiento jurídico.

En un conocido ensayo, Ronald Dworkin afirmó que, en relación con los principios constitucionales -en especial con los derechos- se daba una curiosa paradoja: "todos están de acuerdo en que la Constitución prohíbe ciertas formas de legislación", pero "ni los jueces del Tribunal Supremo, ni los expertos en Derecho constitucional, ni los ciudadanos ordinarios pueden ponerse de acuerdo sobre lo que prohíbe exactamente"15. Después de examinar el lugar que ocupan los derechos humanos en el conjunto de la racionalidad práctica, debemos ser todavía más incisivos que Dworkin: en rigor, la causa de la discrepancia se debe a que los derechos básicos, en su consideración abstracta, no dicen nada -o prácticamente nada- sobre qué está permitido y qué no está permitido.

\section{EL DERECHO POSITIVO COMO DETERMINATIO DE LOS DERECHOS HUMANOS}

El mero reconocimiento de los derechos humanos arroja, como se acaba de señalar, muy pocas conclusiones sobre el recto contenido del Derecho. Son, de hecho, principios "premorales" 16 , en el sentido de que todavía no dicen nada sobre qué ha de hacerse y qué ha de omitirse. Cualquier agente racional obra por mor de alguno de estos bienes humanos, incluido el criminal. Consiguientemente, el aislamiento y absolutización de cualquiera de estos principios constituiría un atentado contra la justicia, tal y como, con su incisiva pluma, advirtió C. S. Lewis en una crítica a los sistemas ideológicos que sustituyen la integración prudencial de la razón práctica por la absolutización de un valor determinado ${ }^{17}$.

En conclusión, la "concreción" de los derechos humanos precisa inequívocamente de la prudencia (phronesis) de la autoridad pública llamada en cada caso a desarrollarlos. En la tradición tomista clásica, esta labor de concreción recibe el nombre de determinatio, y en ella centraremos los siguientes apartados.

\subsection{LO QUE LA DETERMINATIO NO ES}

Para comenzar nuestra explicación del concepto de determinatio, es oportuno aclarar que ella no es la concreción positiva de un conjunto de principios y normas que se derivan en forma deductiva del derecho natural. Una concepción así del derecho positivo y del natural, propia de la escuela del iusnaturalismo racionalista, podría motivar con razón la objeción de que el derecho positivo es, a fin de cuentas, inútil. La objeción ha sido, de hecho, formulada por varios iuspositivistas, y puede encontrarse, por ejemplo, en un artículo de Hans Kelsen, publicado en diciembre de 1949, en el que solemnemente situaba a la "doctrina del Derecho natural" ante el "Tribunal de la Ciencia". Entre las diatribas del célebre jurista austríaco a la filosofía iusnaturalista, le atribuía sostener que la ley positiva solo se justifica en la medida en que se corresponda miméticamente con la ley natural. Como es

15 DWORKIN (1981) p. 468.

16 FinNis (2011a) p. 34.

17 LEWIS (2001) pp. 43-44. 
lógico, sin embargo, semejante pretensión haría superfluo el derecho positivo. En palabras de Kelsen:

"La doctrina de la ley natural se caracteriza por un dualismo fundamental entre derecho positivo y derecho natural. Por encima del imperfecto derecho positivo creado por el hombre, existe un derecho natural perfecto, absolutamente justo, establecido por una autoridad divina. Consecuentemente, el derecho positivo se justifica y es válido tan solo en la medida en que se corresponde con la ley natural. No obstante, si el derecho positivo es válido únicamente en la medida en que se corresponde con la ley natural, y si es posible-como asevera la doctrina de la ley natural- descubrir las reglas del derecho natural mediante el análisis de la naturaleza; si, como afirman algunos autores, el derecho de la naturaleza es incluso autoevidente, entonces el derecho positivo es superfluo. Frente a la existencia de una ordenación justa de la sociedad, inteligible en su naturaleza, la actividad de los legisladores positivos equivale a un esfuerzo estúpido de proveer iluminación artificial a plena luz del sol"18.

En este párrafo, el jurista austríaco tiene a la vista lo expuesto por autores como Hugo Grocio, a quien cita sobre la evidencia del derecho natural lo siguiente: "Los principios de ese derecho [natural], si se les presta una atención exclusiva, son en sí mismos claros y manifiestos, casi tan evidentes como lo son aquellas cosas que percibimos a través de los sentidos; y los sentidos no yerran si es que están bien constituidos y si las demás circunstancias necesarias para la percepción están presentes"19; o Samuel Pufendorf, de su De jure naturae et Gentium: "Verdaderamente, todo el derecho positivo presupone o incorpora al menos los principios generales del derecho natural, gracias a los cuales se conserva segura la raza humana; y estos no son removidos de modo alguno por el derecho positivo, que no es más que un mero añadido a ellos, en la medida en que la situación de cada Estado lo requiera" ${ }^{20}$.

Para que la determinatio sea algo más que "proveer iluminación artificial a plena luz del sol" -como vendría a sugerir la lectura que hace Kelsen del iusnaturalismo racionalista-, es preciso comprender adecuadamente la relación entre los principios universales de la razón práctica -lo que la tradición clásica ha denominado estrictamente "ley natural"- y el derecho positivo. Los principios universales de la ley natural no son otra cosa que los principios universales de la razón práctica, algunos de los cuales pueden categorizarse como "derechos humanos". En el complejo entramado de las relaciones sociales, la protección y promoción de estos principios universales puede adoptar multitud de formas, está abierta a una amplia libertad creativa y no se encuentra "predeterminada" rígidamente, sino que precisa de la prudencia o phronesis del gobernante para concretarse. En palabras de Tomás de Aquino, "se afirma que el derecho positivo procede del derecho natural en cuanto que, a través del derecho positivo, se determina el modo en que ha de observarse el derecho

\footnotetext{
18 Kelsen (1949) pp. 485-486. George (2000) pp. 1625-1646 prueba que la crítica de Kelsen no alcanza al iusnaturalismo de Tomás de Aquino, cuya doctrina ignora por completo en su artículo.

19 Kelsen (1949) p. 485 nota 7. La obra citada es De jure belli ac pacis, Prolegomena, párr. 39.

20 Kelsen (1949) p. 489.
} 
natural"21. A continuación, explicaremos con más exactitud en qué consiste semejante determinación.

\subsection{Lo Que la Determinatio es}

Necesario para comprender el papel que desempeñan los distintos poderes públicos en relación con los derechos humanos, examinaremos el concepto clásico de determinatio ${ }^{22}$. Las relaciones entre, por un lado, el higher law de la ley natural -y, por implicación, de los derechos humanos que se limitan a referir valores o bienes humanos básicos- y, por otro, el vasto y complejo entramado de normas del ordenamiento jurídico-positivo, no es en absoluto una relación de identidad ni de simple deducción, como acaso creyó el iusnaturalismo racionalista del siglo XVIII ${ }^{23}$.

En la Summa Theologiae, I-II, q. 95, art. 2, Tomás de Aquino se planteó justamente si la ley positiva deriva realmente de la ley natural pues, en efecto, "parece" que no ocurre así. Ajeno a cualquier precipitación, el sabio medieval consideró atentamente las objeciones que más inmediatamente saltan a la vista. La segunda de las dificultades que se plantea constituye, curiosamente, una traslación prácticamente literal de la objeción kelseniana apuntada más arriba:

(Obj. b) "Además, el derecho positivo se distingue del derecho natural, según consta por Isidoro en el libro de las Etymol., y por el Filósofo [Aristóteles] en V Ethic. Ahora bien, cuanto deriva de los principios generales de la ley natural a manera de conclusiones pertenece a la ley natural, como se ha dicho. Luego las disposiciones de la ley humana no derivan de la ley natural".

En efecto, si cualquier forma de derivación hubiera de entenderse de modo deductivo -como se halla implícito en la objeción- habríamos de concluir que la ley positiva no puede derivarse de la ley natural, pues ello la haría superflua. Por si quedase alguna duda al respecto, el Aquinate añade dos posibles objeciones adicionales que inciden en el mismo problema:

(Obj. c) "Además, la ley natural es la misma para todos pues, como dice el Filósofo en $\mathrm{V}$ Ethic, lo justo natural es lo que en todas partes tiene la misma vigencia. Así pues, si las leyes humanas derivasen de la ley natural, se seguiría que serían las mismas para todos los hombres, lo cual es patentemente falso".

(Obj. d) "Además, de todo cuanto se deriva de la ley natural se puede dar razón. Pero no puede darse razón de todo cuanto estatuyeron las leyes de los antepasados, como dice el Jurisperito [el Digesto]. Luego no todas las leyes humanas se derivan de la ley natural".

Como puede apreciarse, el mayor exponente de la tradición clásica de la ley natural advierte perfectamente que una relación de identidad o puramente deductiva entre "ley natural" y "ley positiva" haría superflua la "ley positiva" (Obj. b), contradiría la pluralidad

\footnotetext{
21 Super Sent., lib. 4 d. 15 q. 3 a. 2 qc. 1 co.

22 Sobre el concepto tomista de determinatio, ver, por ejemplo, Finnis (2011a) pp. 281-290; y FinNIS (1998) pp. 266-269; Contreras (2011) pp. 39-54; García-Huidobro (1993) pp. 237 y ss.

23 García de Enterría (1963) p. 216.
} 
que existe entre los distintos ordenamientos (Obj. c) y obviaría la creatividad espontánea que encierran las leyes humanas, la cual escapa a la simple racionalización (Obj. d).

Para aclarar las objeciones, el Aquinate explica cuidadosamente el doble sentido en que puede afirmarse que una ley deriva de la ley natural:

En primer lugar, solo en algunos casos puede decirse que, en efecto, un principio del derecho positivo procede de la ley natural como "las conclusiones demostrativas en la ciencia proceden de los principios". Este carácter de simple transposición de exigencias de la razón práctica solo puede aplicarse a algunos principios jurídico-positivos incuestionables para el legislador, por ejemplo, a lo que el iuspositivista Georg Jellinek denominó los "fundamentos indisponibles del derecho penal": "Los fundamentos del derecho penal, por ejemplo, están en buena medida fijados; la prohibición de duros ataques a los bienes jurídicos más importantes no depende de los deseos del Estado. Declarar la despenalización del homicidio está fuera de las posibilidades reales legislativas ${ }^{24}$.

Incluso en estos casos, no obstante, el modo concreto de aplicar un principio indisponible suele estar sujeto a circunstancias contingentes. Así, por ejemplo, la concreción de la criminalización del homicidio se traduce en la fijación de penas que no se encuentran "predeterminadas" por la justicia natural ${ }^{25}$.

En segundo lugar, salvedad hecha de los casos señalados - muy restringidos comparativamente- en que puede hablarse de una derivación deductiva, la ley positiva emana de la ley natural "a semejanza de lo que ocurre en las artes, donde las formas comunes son determinadas (determinantur) en una realización especial, como el artífice, que necesariamente tiene que determinar la forma común de la casa en la figura de esta o aquella casa”. Con carácter general, pues, el derecho positivo procede de la ley o de la justicia natural -incluyamos aquí, como venimos reiterando, los derechos humanos que recogen bienes básicos"por vía de determinación" (per modum determinationis).

¿Qué significa, en este contexto, determinatio? John Finnis lo ha traducido por "implementación" ${ }^{26}$ y cabría admitir otros sinónimos como "concretización” (Konkretisierung), más germánico, o "realización”, más castellano. Para explicar el significado del término, Tomás de Aquino entabla, como se acaba de indicar, una comparación con la labor del artífice o arquitecto que construye una casa. En el caso del arquitecto, el telos de su tarea viene dado de un modo general en la comisión que se le encarga; por ejemplo, construir una casa. Ese telos, sin embargo, constituye simultáneamente una orientación positiva y una constricción negativa, un parámetro-guía y un límite ${ }^{27}$.

En la medida en que la comisión que se le ha confiado actúa como fin o parámetroguía, el arquitecto goza de libertad creativa para concretarla: la medida exacta de las ventanas, por ejemplo, no viene trazada por el comitente pero, en principio, el arquitecto habrá de asegurarse de que las ventanas permitan la entrada de suficiente luz, y la casa será buena o mala en función de factores como la armoniosa disposición de sus distintos elementos,

\footnotetext{
24 JeLLineK (1921) p. 374.

25 Más ampliamente, JellineK (1921) pp. 282-284.

26 FinNIS (2011a) p. 284.

27 De hecho, el concepto griego de telos encierra ambas ideas, "fin" y "límite", Aristóteles, Metafisica, 1021 b.
} 
la coherencia entre unas formas y otras e incluso la belleza con que ejecute su tarea. La libertad creativa es enorme, y ofrece un amplio margen para que juzguemos entre mejores y peores arquitectos. En fin, deja espacio incluso para decisiones basadas en la pura preferencia personal o social, imposibles de someter a veredictos estrictos de justicia.

Exactamente lo mismo sucede con la tarea del legislador. En la medida en que los primeros principios morales -los derechos humanos- actúan como parámetros-guía, el legislador goza de libertad creativa para concretarlos. Piénsese, por ejemplo, en algo tan prosaico como un reglamento de tráfico que, en una sociedad compleja como la nuestra, resulta imprescindible para "implementar" la protección de bienes tan básicos como la vida, la seguridad, la libertad de circulación o la propiedad. Cuál sea el contenido concreto de este reglamento no es derivable de principios universales por vía de deducción, sino por vía de determinación (determinatio). Dependerá de múltiples circunstancias, incluida la propia coherencia interna del reglamento y su coherencia con otras normas existentes. Finalmente, el arte del legislador nos permitirá hablar de mejores o peores reglamentos de tráfico, y habrá incluso un margen de discrecionalidad que se resistirá a cualquier sometimiento a veredictos estrictos de justicia, por ejemplo, la determinación de la cuantía exacta de la multa por saltarse un semáforo en rojo o el límite preciso de velocidad. Como decía Hegel, "es la razón misma la que reconoce que la contingencia" tiene "su esfera y su derecho" 28 .

Hasta ahora nos hemos referido a la dimensión del telos como "fin". El telos, sin embargo, es también "límite", y la comisión encargada al arquitecto tiene una dimensión restrictiva. En cuanto que el encargo recibido actúa como límite, el arquitecto se encuentra constreñido negativamente en su labor implementadora. Se le ha encargado una casa, no una iglesia, ni un hipódromo, ni una cárcel. Tiene un amplio margen de decisión para determinar su forma, pero lo construido habrá de ser un espacio adecuado para habitar.

Lo mismo ocurre con la labor del legislador. En su tarea de implementar los derechos humanos y otros principios universales de justicia, se encuentra sujeto al límite que le imponen los derechos humanos -que no son otra cosa, es forzoso reiterarlo, que bienes básicos, primeros principios de la ley natural-. El legislador no puede implementar un bien o un derecho humano, por importante que sea, a expensas de interferir injustamente, de modo directo o indirecto, en otros bienes humanos básicos. Ahora bien, ¿qué injerencias en un bien o un derecho humano son justas o injustas? Es esto algo que, por sí solos, los derechos humanos no nos indican. Al contrario, solo puede determinarse mediante un juicio de razón práctica atento a las circunstancias concretas.

\section{4. ¿A QUIÉN CORRESPONDE LA DETERMINATIO?}

Todo el derecho positivo - sea en la forma de normas, actos administrativos o decisiones judiciales- supone una determinatio de los derechos humanos y, con carácter general, de los principios básicos que dan forma al bien común. Sentadas las necesarias bases filosóficas, dedicaremos la mayor parte de este trabajo a tratar de definir, más en concreto, las funciones que en este proceso de determinatio competen al legislador y al juez.

28 Hegel $(1820) \$ 214$, p. 179. 


\subsection{El PAPEL DEL LEGISLADOR: FORO DE PRINCIPIOS Y FORO ABIERTO}

Tradicionalmente, la legislación positiva ha sido contemplada como la primera forma de determinatio de los derechos humanos, tal y como explicó, en 1688, el principal teórico moderno de los derechos naturales del individuo. Al decir de Locke, el establecimiento del legislador constituye "el acto primero y fundamental de una sociedad", y resulta completamente ilegítimo transferir su poder a otros ${ }^{29}$. Aun hallándose muy distante, a nuestro modo de ver, de la profundidad de pensamiento y la penetración analítica de Tomás de Aquino, John Locke comprendía en cierto modo la idea de determinatio. Como ha subrayado un conocido estudioso del pensador inglés, gobernar es, para el legislador lockeano, "emitir un juicio público sobre lo que requiere el derecho natural -tanto en lo general como en los detalles- y fijar ese juicio como base de la coordinación e imposición social" 30 (lo mismo que para Tomás de Aquino, como ya hemos visto). Un siglo después de Locke, una idea semejante quedó lapidariamente fijada en el principal catálogo de derechos humanos del Constitucionalismo moderno: los límites de los derechos, afirma el artículo 4 de la Declaración de Derechos del Hombre y del Ciudadano, "no pueden ser determinados más que por la ley".

Es un error, por consiguiente, distinguir las tareas del juez de las del legislador reservando al primero -como ha hecho, por ejemplo, Ronald Dworkin- la dignidad de forum of principle, puesto que ello conduciría a degradar al legislador a un mero forum of policy -sirviéndonos de la propia contraposición de Dworkin ${ }^{31}$. Lejos de ser un simple foro de discusión de policies al servicio del bienestar material de los ciudadanos, el proceso legislativo debe constituir, en su sentido más genuino, un forum of principle. Si se renunciase a conferir al poder legislativo tal dignidad, la voz y el voto de los representantes de los ciudadanos en el orden de los fines se verían seriamente comprometidos. Los asuntos más importantes -esto es, las cuestiones de principio- dejarían de ser objeto de decisión en el Congreso, que se circunscribiría al marco del utilitarismo del bienestar -el ámbito de las policies-. Así, el gobierno representativo cedería su puesto a lo que John Stuart Mill caracterizó como el despotismo benevolente: un régimen en el que "no hay opresión positiva", pero en el que "la inteligencia y los sentimientos de todo el pueblo son abandonados a los intereses materiales"32. La idea de determinatio de los derechos humanos, alrededor de la cual gira este trabajo, ha sido vista por los clásicos del constitucionalismo como una tarea primariamente legislativa ${ }^{33}$.

\footnotetext{
29 LOCKE (1690), en especial $\$ 150$ y $\$ 212$ (cit., pp. 78 y 107).

30 WaLdron (2001) p. 308. Sobre la relación entre ley natural y ley positiva en Locke, WaLdron (1999) pp. 63-91.

31 DWORKIN (1978) p. 82.

32 Stuart Mill (1875) p. 59.

33 Esto explica que los redactores de la Constitución norteamericana concibieran al judicial como el menos peligroso de los poderes, The Federalist Papers, $\$ 78$; cit., p. 412. Aunque este mismo texto sustentaría el poder judicial para revisar la constitucionalidad de las leyes - un poder discutiblemente poco peligroso-, es preciso tener en cuenta que el proyecto de Constitución no incluía un listado de derechos fundamentales (The Federalist Papers, $\$ 84)$.
} 
¿Cómo es posible que, en el Constitucionalismo clásico, la determinatio primaria de los derechos humanos se atribuya a un órgano político como el legislador? ¿No es la protección de los derechos una misión confiada en último término a una instancia técnicamente preparada? A nuestro juicio, es justamente esta premisa la que conviene rechazar. Si pensamos en el lugar que ocupan los derechos humanos en el razonamiento jurídico, de su propia abstracción advertimos que su implementación concreta no depende de consideraciones técnico-jurídicas. Debe elucidarse, por consiguiente, en un foro abierto a cualquier argumento racional, y debe llevarse a cabo no sobredimensionando un interés particular, sino atendiendo al bien del conjunto de la colectividad.

Piénsese, por ejemplo, en un problema actual de derechos humanos como el dilema que plantean las enfermedades catastróficas en relación con el derecho a la vida. Específicamente, podemos preguntarnos: la protección de este derecho, ¿qué obligaciones acarrea para el Estado? La perspectiva desde la que se deben resolver asuntos como este ha de ser muy amplia, y no puede focalizarse en el "derecho a la vida" de la persona que solicita la prestación médica. La forma de asignar los recursos, por definición escasos, se debe centrar en las consecuencias a gran escala que dicha regulación posee para los derechos humanos de todos los sujetos implicados, en el presente y en el futuro.

Analizando así las cosas, nos percatamos de que una regulación laxa, que facilite la prescripción de tratamientos médicos, sin mayores reparos, en nombre del "derecho a la vida" de las personas que lo solicitan, induce a la desprotección de otros potenciales beneficiarios del sistema, que verán mermadas sus posibilidades por la disminución de los recursos disponibles. Asimismo, debilita el orden de las políticas públicas, al quedar sujeta su priorización a la contingencia que supone la aparición de enfermedades catastróficas no presupuestadas. Y, por cerrar la letanía de consecuencias, que sin duda podría alargarse, con el tiempo se extendería a otras necesidades propias del derecho a la vida, así como de otros derechos fundamentales.

Huelga decir que tampoco la simple denegación del tratamiento sería una respuesta adecuada, sino que habría de buscarse una solución que, sin incentivar una demanda virtualmente imposible de satisfacer, ofreciese una respuesta digna para quienes padecen enfermedades catastróficas. Lo que parece inadmisible, desde luego, es que la solución se focalice exclusivamente en las situaciones de excepción. Sin embargo, esto es exactamente lo que ha ocurrido en la determinatio judicial del derecho a la vida: un interés -el del individuo que sufre una enfermedad catastrófica- se coloca en pie de igualdad -y aun de superioridad- frente a una multiplicidad de intereses que, en casos como este, también están conectados con los derechos humanos y afectan a toda la sociedad ${ }^{34}$. Para que el entero abanico de intereses reciba una atención adecuada, la prudencia legislativa debe poder desplegarse sin cortapisas. Ha de enmarcarse en un foro político abierto, liberado de las restricciones del discurso inherentes a los procesos judiciales de derechos ${ }^{35}$.

\footnotetext{
34 Díaz Hernández con Fondo Nacional de Salud, Servicio de Salud de Concepción y Ministerio de SaLUD (2018). Este resultado no es una anomalía del proceso judicial, sino su consecuencia propia. Como señala TAYLOR (1992) p. 116, la lógica intrínseca de los bienes concebidos como derechos reclama del juez una satisfacción integral; si no, no serían derechos.

35 En una línea similar a la aquí defendida, Yowell (2018) capítulo 5.
} 
La naturaleza abierta del foro legislativo se corresponde con la función de legislar, que apunta generalmente al futuro ${ }^{36}$. La responsabilidad del órgano legislativo es crear o modificar las reglas por las que se regirán las partes en el porvenir, mientras que la responsabilidad del judicial es aplicar las reglas vigentes al momento en que se generó el conflicto entre las partes. El primero mira a lo que será y el segundo a lo que fue; el primero crea derecho y el segundo lo aplica ${ }^{37}$. Por ello es que no existe una razón artificial que restrinja el discurso o proceso deliberativo más allá de las formas procedimentales de elaboración de la ley, ya que a través de él se trata de definir lo justo, no de encontrarlo ${ }^{38}$.

Esta diferencia con la función judicial que, por su naturaleza, apunta hacia el pasado, explica que el rango para la determinatio legislativa sea mucho más amplio que el de los jueces. La esencial incertidumbre del futuro se puede representar como una hoja en blanco sobre la cual el legislador traza con libertad sus líneas, siempre dentro de los bordes del papel $^{39}$. Para los jueces, en cambio, el espacio en blanco del papel viene limitado por una serie de condicionantes, como son los hechos del caso, los argumentos esgrimidos por las partes, las normas aplicables, los precedentes judiciales, etc.

El foro abierto caracteriza la deliberación legislativa en una democracia representativa, porque esta deliberación es un ejercicio de autogobierno y, en cuanto tal, goza -o debería gozar- de la libertad para darse las reglas que estime convenientes y oportunas ${ }^{40}$. A esto habría que añadir la creencia de que la mejor respuesta posible surgirá de un debate abierto de las ideas ${ }^{41}$, y que la diversidad de la sociedad está mejor representada en un foro donde todo es debatible. En último término, el foro abierto es una condición exigida por la naturaleza de la política, que excluye la existencia de respuesta correctas a priori ${ }^{42}$.

\subsection{El PAPEL DE LA JURISDICCIÓN: DOS MODELOS POSIBLES}

$\mathrm{Si}$, como hemos visto, es tarea del legislador positivo "implementar" o "determinar" los derechos humanos, ¿en qué queda la misión del juez al respecto? Si todo el derecho positivo puede caracterizarse como determinatio de los derechos humanos, ¿no ha de verse el juez degradado a la simple condición de "bouche qui prononce les paroles de la loi” 43 ? Y si,

\footnotetext{
36 Yowell (2018) loc. 2896. Así, por lo demás, lo declara el artículo 9 del Código Civil chileno. Para FulLer (2019) pp. 53-64, el carácter prospectivo de la ley es una de las condiciones de la moral interna del Derecho.

37 FInNIs (2015), para quien la distinción es compatible con el reconocimiento del desarrollo judicial del Derecho, en la medida que se entiende como resultado de una nueva interpretación de las reglas vigentes y no de la introducción de nuevas reglas.

38 Estas reglas procedimentales, en realidad, no deben entenderse como una restricción a la amplitud del foro, sino una condición para su posibilidad, WALDRON (2006) p. 29.

39 Las decisiones legislativas son, desde esta perspectiva, definitorias de un "mundo nuevo", "un mundo ahora configurado por una decisión que razonablemente pudo haber sido diferente”, WebBER (2018) p. 50.

40 Waldron (2006) p. 23.

41 Mill (1869) p. 33.

42 Esta premisa debe entenderse relativizada por los límites constitucionales al poder legislativo, un poder que no es soberano, sino que se ejerce en representación del soberano. El poder que el Congreso tiene para modificar los límites constitucionales no invalida lo anterior, porque entonces actúa como poder constituyente (derivado) y no como legislador.

43 Montesquieu (1748) XI, 6.
} 
por el contrario, el juez ostenta alguna misión en la determinatio de los derechos humanos, ¿qué distingue su papel de la labor del legislador?

\subsubsection{El modelo judicial: actividad cognitiva, razón técnica y rule of law}

Para dar respuesta a los interrogantes recién apuntados, comenzaremos este epígrafe subrayando tres singularidades del proceso judicial que lo diferencian netamente de las actividad legislativa o gubernativa: a) su carácter estrictamente cognitivo; b) la sujeción del juez a una razón técnica; y $c$ ) la relativa predeterminación normativa del oficio judicial.

a) En un inteligente ensayo, el profesor Rubio Llorente afirmó que, en relación con los derechos humanos, la diferencia entre los órganos políticos y judiciales estaría en que lo específico del juez es garantizar el "respeto" de los mismos, mientras que lo propio del resto de poderes públicos sería llevar a cabo su "realización”4. Esta caracterización de Rubio coincide con el doble carácter, arriba señalado, de la determinatio de los derechos humanos. Como se ha explicado, estos operan, de un lado, como parámetros-guía que orientan el proceso de creación del derecho positivo; y de otro, como límites que le ponen coto. En opinión de Rubio, al juez competería únicamente fijar los "límites" de la determinatio de los derechos, en tanto que el despliegue positivo de los mismos se mantendría en manos del poder político. Partiendo de esta base, el reconocido constitucionalista español criticaba la expansión activista de las instituciones judiciales en la promoción positiva de los derechos y reivindicaba la idea clásica de los derechos civiles como límites negativos al ejercicio del poder.

A nuestro modo de ver, el trabajo de Rubio apunta cabalmente al carácter cognitivo de la labor judicial, muy alejado de los amplios márgenes de libertad creativa que son propios del legislador. Y es que, efectivamente, el acto de implementación o realización de los derechos, entendidos como parámetros-guía, posee un fuerte carácter volitivo discrecional: supone una elección entre múltiples opciones más o menos razonables e incluso una dosis de arbitrariedad. Al contrario, determinar los límites que los derechos imponen constituye un acto eminentemente cognitivo.

Dado que la del juez es una labor de cognición, resulta claro que se halla mejor preparado para fijar los límites negativos que imponen los derechos que para promover su mejor implementación positiva. Establecer si la negativa de una aseguradora a pagar por una determinada prestación de salud lesiona los límites que impone el derecho a la salud o a la vida, es, en principio, un acto de conocimiento (de los límites). Mientras que determinar si se incrementa o no la cobertura de la Seguridad Social para tutelar mejor la vida de un cierto grupo de personas, es un acto de creación, fruto de la elección presupuestaria entre múltiples opciones razonables. Dicho esto, el carácter cognitivo de la función judicial es tan solo uno de los rasgos de la labor propia de los órganos judiciales, y no basta constatar el carácter cognitivo de la determinación de los límites de los derechos para afirmar que es competencia de los jueces. Para esclarecer lo propio del oficio judicial resulta necesario añadir, al menos, dos rasgos adicionales: razón técnica y predeterminación del Derecho.

b) Es propio del juez, en efecto, el empleo de la razón técnica del Derecho, y no simplemente de la razón natural humana. Para comprender a fondo esta especificidad del saber

44 Rubio (2006) p. 203 y ss. 
jurídico, es oportuno remitir a la penetrante clasificación de los saberes u órdenes que hizo Tomás de Aquino según los "cuatro modos" en que "el orden se relaciona con la razón" ${ }^{2}$.

Al propósito que aquí interesa, ha de indicarse que, en tanto que saber práctico, el Derecho tiene la peculiaridad de ser al mismo tiempo un saber moral acerca de la praxis, o sea del recto obrar (tercer orden); y un saber técnico acerca de la poiesis, o sea de los productos de nuestras acciones (cuarto orden).

Habida cuenta de que el Derecho pertenece al orden de los saberes técnicos, lo que especifica al juez como profesional del Derecho y lo distingue del simple lego no es su probidad moral -que, indudablemente, habrá de poseer para ser un buen juez, lo mismo que el médico ha de poseerla para ser un buen médico- sino el hecho de operar con arreglo a una razón técnica ${ }^{46}$. A ello se refirió uno de los jueces más célebres de la Modernidad temprana, Sir Edward Coke, en los siguientes términos: "Nihil quo est contra rationem est licitum; puesto que la razón es la vida del Derecho, es más, el common law mismo no es otra cosa que razón; lo cual ha de entenderse como perfección artificial de la razón, adquirida mediante largo estudio, observación y experiencia, y no como la razón natural de todo hombre, ya que nemo nascitur artifex" ${ }^{37}$.

Las reglas del discurso legal articulan los modos de argumentar del jurista e incapacitan al lego para participar en la discusión. Ello se debe a que, en el complejo entramado de la sociedad, los principios universales de justicia dan forma a una infinidad material de hechos vitales históricos y contingentes. Congruentemente, la justicia toma cuerpo en una vasta creación cultural, como se ha indicado, compuesta por topoi normativos de diversa índole cuya interpretación y aplicación exige un profundo conocimiento y estudio: reglas lógicas, definiciones, apotegmas autoritativos (reglas de experiencia, opiniones notables de justicia relativas a ámbitos concretos de las relaciones sociales...), precedentes jurisprudenciales, normas jurídico-positivas, etc. ${ }^{48}$. El razonamiento judicial, valga la insistencia, es simultáneamente un razonamiento moral y un razonamiento técnico, porque el Derecho pertenece simultáneamente al orden ético de la acción (praxis) y al orden técnico del arte (poiesis) ${ }^{49}$.

c) Finalmente, es también propio de la labor del juez el hallarse determinada por el rule of law. Reiterando lo dicho por Rubio -que se hace eco, a su vez, de una expresión acuñada por el jurista suizo Werner Kägi-, podemos afirmar que la razón jurídica opera dentro de un orden de Derecho, no simplemente de los dictados morales de la justicia: Rechtssaat kein Gerechtigkeistaat ${ }^{50}$. Al igual que la legislación, también la judicatura constituye un forum of principle. Ahora bien, el orden jurídico-positivo tiende a enmarcar la discrecionalidad de los jueces, una aspiración multisecular que se encuentra ya presente en

\footnotetext{
45 Así, por ejemplo, en Sententia libri ethicorum $(\mathrm{I}, 1)$.

46 A este respecto, sigue siendo actual el debate habido en 1521-1522, entre Martín Lutero y Tomás Moro, en que el primero defendía que las leyes son superfluas y bastan los buenos jueces, mientras que el segundo defendía la necesidad de las leyes, aunque los jueces fueran buenos, CORRAL (2011).

47 Coke (1628) 97b, Vol. 1, p. 337.

48 Finnis (2011b) pp. 219-220.

49 Para la distinción aristotélica entre praxis y poiesis, ver, por ejemplo, TOMÁs DE AQUINO, Sententia libri ethicorum, I, 12, \$144.

50 KäGI (1953) p. 178. En la obra de Rubio (2006) pp. 205 y 208.
} 
la Retórica de Aristóteles ${ }^{51}$. Semejante predeterminación nunca llegará hasta el punto de degradar al juez a mera "bouche qui prononce les paroles de la loi", pero confinará su libre arbitrio a unos límites razonables ${ }^{52}$.

Con los mimbres trazados, volvamos ahora sobre el problema de la determinatio de los derechos humanos. Dejando al margen las cláusulas de derechos que fijan reglas concretas, concebir como "judicial", por contraposición a "política", la tarea de determinar el contenido de los derechos humanos abstractos - los bienes humanos básicos-, y hacerlo al margen o por encima del legislador supone, como a continuación indicaremos, una dudosa atribución.

En efecto, si admitimos que la sumisión a un derecho predeterminado y la razón técnica constituyen rasgos propios de la labor judicial, entonces existen serias razones para cuestionar la competencia del juez respecto a la determinatio de los derechos humanos. En la medida en que los derechos no consignan reglas claras, sino que afirman valores o bienes humanos básicos, no son otra cosa que primeros principios del razonamiento práctico. Consecuentemente, la labor de fijar sus límites no solo no está predeterminada por normas jurídico-positivas, sino que no debe estarlo; y no solo no es asunto de la razón técnica, sino que no debe serlo. Al contrario, teniendo en cuenta las consecuencias que esos límites poseen para múltiples derechos humanos de la comunidad en su conjunto, su determinación constituye un acto de prudencia legislativa en sentido estricto. Por ejemplo, si la libertad de conciencia contempla el derecho a objetar el servicio militar obligatorio o no, es una cuestión que debe ponderarse junto a una serie de otras consideraciones (v.gr. seguridad nacional) distintas al interés individual del pacifista. Una decisión al respecto constituye un acto de prudencia natural en toda regla, no de razón técnica ${ }^{53}$.

Debe añadirse, a fortiori, que el aparato técnico-racional que, por su propia formación profesional, tienden a crear los juristas, entorpece de hecho el razonamiento moral natural al que debe estar sometida la determinatio primaria de los principios fundamentales de la razón práctica, incluidos los derechos humanos. La razón artificial del Derecho constituye una buena herramienta o un "siervo útil" para manejar un vasto corpus jurídico-positivo, pero resulta un "mal señor" para determinar primariamente los límites de los derechos y libertades.

Así, por usar un ejemplo relativamente reciente de la jurisprudencia chilena, el caso del ejercicio del derecho a sufragio de ciudadanos privados de libertad. En una serie de sentencias de protección, la Corte Suprema ordenó a los recurridos -el Servicio Electo-

\footnotetext{
51 Retórica, $1354 \mathrm{a}$

52 De hecho, el juez también practica la determinatio, solo que para una situación particular, FinNIS (1998) p. 267 y nota 81 .

53 NN CON DiReCtor GENERAL DE MOVILIZACIÓN NACIONAL (2003), rechazó un recurso de protección contra la regulación del servicio militar obligatorio, que sería inconstitucional por no contener una excepción para los objetores de conciencia. La sentencia empatizó con los recurrentes, pero se excusó diciendo que "el derecho es una elaboración a futuro que supone definiciones adoptadas y asumidas por los detentores de la soberanía nacional, ante variadas alternativas (...). [La regulación cuestionada] es fruto de proyecciones ora filosóficas, ora morales, ora sociológicas y hasta de otra índole (...). Buena o mala, tal [regulación] no puede ser desconocida por la jurisdicción. (...) Ergo, mientras la voluntad política no establezca otra modalidad, la Corte se atiene, al emitir su juicio, al esquema claramente construido por el ordenamiento" (cons. 11\%). La sentencia fue apelada ante la Corte Suprema y declarada inadmisible por falta de peticiones concretas, en sentencia de 25 de junio de 2003, rol 2270-2003.
} 
ral y Gendarmería- disponer lo necesario para que los presos pudieran sufragar ${ }^{54}$. Con la atención puesta en el individuo y sus derechos fundamentales (de expresión, igualdad y políticos), el Tribunal ignoró los argumentos que imposibilitaban cumplir con lo ordenado. Estos argumentos, sin embargo, radicaban en el diseño mismo del sistema electoral, en que el domicilio del elector cumple una función estructurante. Puesto que los lugares de reclusión no son el domicilio de los reclusos, permitirles votar significaría una alteración de las bases del sistema.

La decisión de este problema no debería depender del sometimiento de un catálogo de valores o bienes básicos yuxtapuestos (los derechos humanos) a una serie de reglas técnicas de interpretación, argumentación y procedimiento. Al contrario, el juicio prudencial al respecto es tributario de una infinidad de circunstancias que, accesibles a la razón moral natural, no puede encorsetarse en los estrechos límites de una dogmática de los derechos, ni sujetarse a las reglas y presunciones del procedimiento judicial. Esto fue lo que, indirectamente, vino a reconocer la misma Corte Suprema cuando rechazó un nuevo recurso de protección, argumentando que "el conflicto planteado en autos excede con creces los márgenes, en general de una acción netamente jurisdiccional (...), siendo de advertir que la pretensión hecha valer hace indispensable la dictación de normas legales que son de iniciativa exclusiva de los órganos colegisladores" ${ }^{55}$.

Pese a la satisfacción con que los constitucionalistas tendemos a contemplar el imponente edificio dogmático a que han dado lugar los derechos humanos, lo cierto es que, a la hora de determinar primariamente los límites que semejantes derechos imponen al legislador, dicho edificio supone un corsé que oprime inconvenientemente la razón moral natural.

Pero no nos engañemos, porque la razón moral natural tiende a "rebelarse" justamente y hacer inútil el corsé. En este sentido, si en algún ámbito opera la llamada "creación libre" del Derecho es en la jurisprudencia de derechos humanos ${ }^{56}$. Adviértase que esto no constituye, en sentido estricto, un reproche a la actitud de los juristas, ya que no pueden obrar de otra manera. Como se ha dicho, es la razón natural misma la que procura resistirse a la tecnificación del proceso de determinatio del contenido de los derechos humanos. Así pues, lo que denominamos "creación libre" no es propiamente un acto de volición arbitraria sino una decisión que, basada en el razonamiento y la intuición moral natural, se construye técnicamente a posteriori -en ocasiones, sin advertirlo siquiera el propio razonador práctico, que inconscientemente selecciona sus métodos desde la precomprensión (Vorverständnis) ${ }^{57}$ de partida-. Lo que aquí se subraya no es la ausencia de la precomprensión en otros ámbitos del Derecho, sino el carácter determinante que cobra cuando los criterios de corrección técnica arrojan poca luz a la justicia del problema concreto. La tendencia a la llamada "creación libre" en el ámbito de los derechos humanos es la consecuencia necesaria de la tesis central

\footnotetext{
54 Por todas, Instituto Nacional de Derechos Humanos contra Servicio Electoral y Gendarmería de Chile (2017).

55 Marelic con Servel y otro (2017) cons. $4^{\mathrm{o}}$.

56 SIMÓN (2018) pp. 89-112; y “La interpretación de los derechos en perspectiva teórica y práctica”, en RuBIO y otros (2016) pp. 895-918.

57 Procedente de la hermenéutica de GADAMER, la relevancia de la "precomprensión” para la interpretación jurídica fue correctamente enfatizada por EsSER (1972).
} 
de este trabajo: la determinatio primaria de los derechos humanos atañe sustancialmente a la razón moral natural, y más en concreto a la prudencia política.

Teniendo en cuenta los denodados esfuerzos de la iuspublicística de finales del siglo XX por reivindicar -también en el ámbito de los derechos humanos- un saber basado en la "justificación de artesanía jurídica" ${ }^{8}$ por contraposición a la simple razón natural, tal vez nos encontremos ante una verdad incómoda, difícil de digerir. Pero lo cierto es que los hechos la proclaman obstinadamente: los valores y bienes más abstractos constituyen bienes humanos básicos cuya determinatio, positiva y negativa, no depende -al menos no primariamente- de la artesanía jurídica. En ello han concordado, paradójicamente, el mayor representante del iuspositivismo del siglo XX, Hans Kelsen, y el mayor representante contemporáneo del iusnaturalismo jurídico, John Finnis. Filosóficamente en las antípodas, ambos han comprendido excepcionalmente bien lo propio de la técnica jurídica. Advirtiendo el tipo de razonamiento que subyace a la determinación de los derechos humanos, el gran jurista austríaco se opuso a que la razón natural del legítimo representante de los ciudadanos fuese fiscalizada por la razón natural -envuelta en apariencias técnicas- del Tribunal Constitucional ${ }^{59}$. Casi sesenta años después, con argumentos basados no tanto en la democracia cuanto en el rule of law, el iusnaturalista John Finnis hizo una crítica muy similar en su Maccabean Lecture pronunciada ante la Academia Británica ${ }^{60}$. Y es que, en definitiva, la disputa que tenemos entre manos no se dirime en el campo de batalla del iusnaturalismo contra el iuspositivismo, sino en el cabal entendimiento de la naturaleza de la determinatio de los bienes humanos básicos a los que se orientan nuestras inclinaciones.

\subsubsection{El modelo de aristocracia politica}

En el epígrafe anterior, hemos tratado de mostrar lo alejada que está la determinatio primaria del contenido de los derechos fundamentales respecto del paradigma del oficio del profesional del Derecho, dentro del que incluimos al juez. Para ello, nos hemos basado en dos rasgos que caracterizan la actividad judicial en su significado focal ${ }^{61}$ : de un lado, es una labor considerablemente predeterminada por reglas de Derecho y, de otro, obedece a la razón técnica. Por el contrario, la determinatio primaria de los derechos humanos abstractos no se encuentra considerablemente predeterminada por reglas de Derecho. Además, ni está acotada ni debe estar acotada por la razón técnica, sino que ha de guiarse por la prudencia política natural. ¿Supone esto un rechazo a la posibilidad de cualquier tipo de control sobre el legislador en su labor de determinatio? Semejante conclusión sería precipitada, puesto que no se sigue de la crítica que venimos haciendo. Lo único que se ha rechazado arriba es que el control que ejercen los jueces sobre el legislador con base en los derechos humanos responda

\footnotetext{
58 García de Enterría (1981) pp. 222 y ss.

59 Kelsen (1929) pp. 68-70.

60 FinNis (2011c) pp. 19-46.

${ }^{61}$ La expresión "significado focal" (focal meaning) se utiliza con referencia a la homonimia pros hen a partir de OWen (1960) pp. 180-199. Sobre la homonimia o equivocidad "por referencia a algo" (pros hen), a saber, a un caso paradigmático o central, Aristóteles, Metafísica, IV, 2, 1003a-b (en relación con "el ser" y "la salud"); Ét. Nic., 1096 b (en relación con "el bien”) y 1159a (en relación con "la amistad"); Ét. Eudemia, 1236a (también en relación con "la amistad”); y Política, 1275a- b (en relación con "la ciudadanía”).
} 
al paradigma judicial de la razón técnica y la predeterminación del Derecho. En ningún momento se ha sostenido, sin embargo, que dicho control no sea posible ni aun deseable.

Ahora bien, si no responde al paradigma judicial de la razón técnica, la pregunta inevitable es: ¿a qué paradigma responde? Por difícil de asumir que sea desde un punto de vista radicalmente democrático, la respuesta es, a nuestro juicio, que responde a un modelo de aristocracia política -o juristocracia, en la tesis de Hirschl- ${ }^{62}$. Esta tesis no debe considerarse en sí misma como una crítica. De hecho, firmes e inteligentes defensores de la democracia constitucional en nuestro tiempo -v. gr., el filósofo político suizo Martin Rhonheimer- han apuntado que, lejos de ser una democracia pura, la nuestra constituye un retorno a la admirada constitución mixta de los medievales, bajo las condiciones, eso sí, del Estado moderno. En sus propias palabras, "el Estado constitucional (presupuesto de cualquier democracia moderna auténtica) constituye en cierto sentido una 'vuelta atrás' del principio 'puro' de la estatalidad moderna, tal y como fue realizado en la Modernidad temprana. Esta 'vuelta atrás' recupera la herencia de una larga historia, una recuperación que se realiza, sin embargo, sobre la base de la fundación creada precisamente por el Estado territorial moderno. En cierto sentido, estamos tratando con una síntesis histórica en la que la idea del regimen mixtum se ha realizado como nunca antes"63.

En este regimen mixtum, ¿dónde reside el elemento aristocrático, sino en la Jurisdicción constitucional? Toda vez que captamos que la determinatio de los derechos humanos constituye una tarea de la prudencia humana natural, el ejercicio de la jurisdicción de los derechos humanos sobre el legislador ha de considerarse, en efecto, como un oficio aristocrático en nuestro sistema de gobierno. Esta premisa -que la political correctness hace difícil de admitir, en nuestra opinión; y que el rigor intelectual hace difícil de negar-implicaría aceptar que los jueces razonen como políticos, al menos cuando vienen a determinar primariamente el contenido de los derechos fundamentales. Esto es precisamente sobre lo que se quiere llamar la atención, al caracterizar al Tribunal Constitucional chileno como una tercera cámara legislativa: "[se dice que el del Tribunal Constitucional] es fundamentalmente un juicio 'técnico-jurídico', donde las pasiones políticas están fuera de lugar. Como consecuencia de esto, cuando deben opinar sobre cuestiones constitucionales, hablan como quien no está defendiendo sus convicciones políticas, sino describiendo técnicamente el derecho. (...) Ahora bien, esto es una ilusión, porque se trata de la misma discusión, con los mismos argumentos, y lo que lo hace más notorio, con las mismas alineaciones políticas. (...) Y, por consiguiente, cuando el Tribunal debe decidir, lo que hace es elegir entre una interpretación de derecha o izquierda, no adjudicar imparcialmente conforme a derecho. Aunque se llame 'tribunal', el Tribunal Constitucional es una tercera cámara legislativa" ${ }^{44}$.

En la medida en que el modelo aristocrático explica mejor lo que realmente está ocurriendo cada vez que los jueces realizan una determinatio primaria de los derechos fun-

\footnotetext{
62 Hirschl (2004).

${ }_{63}$ Rhonheimer (2013) pp. 26-27.

${ }^{64}$ Atria y Salgado (2015). También cabría identificar al juez que decide al margen de las categorías técnicojurídicas con la función administrativa, que ATRIA (2016) pp. 240-241, caracteriza como la "transformación del [juez] activista en comisario", es decir, un juez que da a cada uno lo suyo "a la manera del derecho pre-moderno, apelando inmediatamente a la razón”. Sobre la noción de derecho pre-moderno, ATRIA (2016) pp. 56-63.
} 
damentales, es preferible al modelo judicial. Por supuesto que este cambio de paradigma exigiría replantearnos el papel que deben desempeñar las categorías técnicas en la determinación de los derechos humanos ${ }^{65}$.

\subsection{Naturaleza de la Determinatio y Desviación Individualista de la DOGMÁTICA}

Tras haber examinado lo propio de la labor del legislador, así como los dos modelos posibles de jurisdicción constitucional, quisiéramos concluir nuestro estudio reincidiendo en el examen crítico, apenas esbozado, del lugar que ocupa el razonamiento técnico en la determinatio de los límites del legislador. Más en concreto, cuestionaremos una peligrosa desviación individualista de la dogmática y la jurisprudencia de derechos humanos, anticipada en cierto modo al estudiar el papel del legislador. A través de lo que suele denominarse tutela multinivel ${ }^{66}$, los derechos humanos esgrimidos por los individuos cobran una vis expansiva que tiende a subestimar las razones de orden público y de bien común, ignorándose que de las razones de orden público dependen rigurosamente los derechos humanos del conjunto de la sociedad.

El modelo judicial de la determinatio de los derechos humanos conduce a que el proceso se centre en los intereses y agravios esgrimidos por el recurrente, el cual monopoliza injustamente el papel de potencial víctima. De este modo, se pasa por alto que un exceso en la definición de los derechos de cualquier clase de individuos se traduce automáticamente en la desprotección de los derechos de terceros. La determinatio primaria de los derechos humanos -tanto la implementación de su contenido como la determinación de sus límites- no debería sobredimensionar el interés de ningún individuo en concreto, sino atender simultáneamente a la afectación de los intereses del conjunto de los ciudadanos, esto es, al bien común. Si de la aplicación estricta de una normativa buena para preservar el bien común -en el cual están comprometidos los derechos humanos de todos los ciudadanos- se deduce un perjuicio hacia un individuo concreto, dicho perjuicio debería corregirse mejorando la norma positivamente -esto es, legislando- o moderando su aplicación desde los cánones de equidad propios de la prudencia jurídica. La opción de invalidar la norma en nombre de los derechos humanos de ese solo individuo es mucho más problemática, porque oscurece la función protectora de los derechos de los demás ciudadanos que dicha norma cumple.

Conviene detenerse en un ejemplo que pone de manifiesto con toda claridad la falsa distinción entre razones de derechos humanos -las cuales tienden a cobrar un valor preferente en el procedimiento judicial-y razones de orden público o de bien común. Aunque cabría citar un sinfín de casos para ejemplificar esta tesis, una ilustración palmaria la ofrece,

\footnotetext{
65 Anejo a esta cuestión está el dilema de hasta qué punto el ejercicio de esta determinatio tiene que estar reservada estrictamente a técnicos en Derecho y no debe abrirse, más bien, a otro tipo de personalidades con una acreditada trayectoria de excelencia y probidad en el servicio público, como ya ocurre en algunos países.

${ }^{66}$ Como pequeño botón de muestra, Freixes (2016) pp. 23-38; y Bilancia (2006) pp. 255-277.
} 
a nuestro juicio, el caso Paradiso Campanelli c. Italia, referente al problema de los vientres de alquiler ${ }^{67}$.

Los recurrentes del caso eran un matrimonio italiano de cierta edad que, tras intentar varias veces sin éxito procrear mediante fecundación in vitro, contrataron con una empresa rusa, por 50.000 euros, servicios de vientre de alquiler para hacer efectivo su deseo. Especializada en técnicas de reproducción asistida, la empresa realizó una fecundación in vitro y afirmó implantar un embrión -fecundado supuestamente con el óvulo de una donante anónima y con el semen del recurrente- en la madre portadora. El bebé nació en febrero de 2011; en marzo, la pareja italiana fue inscrita en Rusia como progenitores del niño, sin mención alguna de la gestación en vientre de alquiler; y en abril, la madre obtuvo en el Consulado italiano los documentos que le permitían volver con el niño a Italia. En mayo, sin embargo, el Consulado de Italia en Moscú comunicó a las autoridades administrativas y judiciales italianas que el expediente sobre el nacimiento del menor contenía datos falsos. Los recurrentes fueron imputados por alteración del estado civil y falsedad documental, ya que habían recogido a un niño que no era suyo, y lo habían hecho violando la legislación de adopción, que impedía adoptar un niño de tan corta edad. En el curso del procedimiento se llevó a cabo una prueba de $\mathrm{ADN}$ en la que se verificó, además, que el recurrente no era padre del niño.

En octubre de 2011, el Tribunal de Menores ordenó el alejamiento de los padres del menor, aportando numerosas razones. Se destacaban, entre otras causas, que se habían violado las disposiciones de adopción internacional, y que el acuerdo firmado por los demandantes con la empresa rusa era contrario a la ley italiana de procreación asistida, la cual prohíbe la fecundación asistida heteróloga. La situación creada era completamente ilegal, y el Tribunal entendía que lo procedente era alejar a los demandantes del niño y darlo en adopción. Advertía el órgano judicial que, "dado que los demandantes habían preferido burlar la ley de adopción a pesar del acuerdo que habían obtenido, se podría pensar que el niño era el resultado de un deseo narcisista de la pareja, o incluso que estaba destinado a resolver los problemas de pareja". Ello le llevaba a dudar de "su capacidad real emocional y educativa". Por consiguiente, en aplicación de la ley italiana de adopción, se nombró un tutor para el niño, que fue confiado a los servicios sociales y dado en acogida en enero de $2013^{68}$.

Después de oponerse sin éxito a estas medidas utilizando todas las vías jurídicas disponibles en Italia, los recurrentes llegaron al Tribunal Europeo de Derechos Humanos. Mediante Sentencia de 27 de enero de 2015, el Tribunal de Estrasburgo condenó a Italia por vulnerar el derecho a la vida familiar del artículo 8 del Convenio. La Sentencia enunciaba muchos de los elementos del caso y, en una ponderación de conjunto, consideraba que el argumento del orden público debía ceder frente al interés de los recurrentes en mantener su convivencia afectiva -a pesar de que dicha convivencia tan solo había durado unos meses-. Lo más llamativo de la decisión es, a nuestro juicio, la poca sensibilidad del Tribunal frente al bien común protegido por el orden público. En efecto, se refiere al argumento del orden público restric-

\footnotetext{
67 Paradiso Campanelli C. Italia (2015) Tribunal Europeo de Derechos Humanos; y Paradiso Campanelli C. ITALIA (2017), Gran Sala del Tribunal Europeo de Derechos Humanos.

68 Paradiso Campanelli C. Italia (2015) Tribunal Europeo de Derechos Humanos.
} 
tivamente, para ponerle coto, ignorando el vínculo que existe entre la preservación del orden público de una comunidad -en este caso, el Estado italiano- y los mismos derechos humanos de los niños de esa comunidad. En contraste, otorga un elevado peso a los aspectos emocionales individuales del caso, incluidas las dificultades para procrear del matrimonio, las cuales, en realidad, constituyen una circunstancia incapaz de justificar un hecho ilícito contra el estado civil, y menos de justificarlo en términos de derechos humanos ${ }^{69}$.

Pese a que la decisión fue revocada ${ }^{70}$, un somero examen de la dogmática jurídica y las herramientas técnico-argumentativas empleadas por Estrasburgo conduce a caer en la cuenta de que cualquier injerencia en un derecho está sometida a una excesiva presunción de ilegitimidad ${ }^{71}$. Si a ello añadimos que solo los individuos pueden invocar el poderoso argumento que son sus derechos humanos, advertimos que el bien común, de cuya tutela penden los derechos humanos del conjunto de su población, se encuentra en una injusta situación de desventaja. En el caso recién mencionado, únicamente en el pronunciamiento de la Gran Sala -decidido por 11 votos contra 6- se admitió que "el fin legítimo de prevenir el desorden" está vinculado a "la protección de los niños, no solo de los niños en el presente caso sino de los niños más generalmente" 72 .

Sería un error creer que esta fuerte desviación individualista es exclusiva de la jurisprudencia de Estrasburgo, por más que el activismo de este Tribunal -debido a causas no estrictamente técnicas- haya sido particularmente llamativo. En realidad, el individualismo ha permeado ampliamente la dogmática prevalente de los derechos, cuyo contenido tiende a ser definido de modo muy extenso. La teoría amplia del "ámbito de protección" (Schutzbereich) tutelado prima facie por los derechos es doctrina dominante, y encuentra un reflejo en una popular teoría de los derechos ${ }^{73}$. Al mismo tiempo, se apuesta por una fuerte presunción en contra de las restricciones en los derechos abstractamente considerados, presunción que viene encarnada en las severas exigencias del principio de proporcionalidad, especialmente en sus exigencias de necesidad. La conjunción de ambas ideas -supuesto de hecho amplio, restricciones sujetas a una seria presunción en contra- arrojan como conclusión una peligrosa tendencia individualista.

\section{CONCLUSIÓN}

Freedom for the pike is death for the minnows - "la libertad para el lucio es la muerte para los pececillos", recordaba sabiamente Isaiah Berlin en Two Concepts of Liberty ${ }^{74}$ La garantía de los derechos fundamentales debe entenderse como un esfuerzo coordinado entre el juez y el legislador, al suponer esa tarea un delicado equilibrio entre los intereses individuales y sociales. La determinatio es un concepto útil para articular ese esfuerzo, al es-

69 Paradiso Campanelli c. Italia (2015) Tribunal Europeo de Derechos Humanos.

70 Paradiso Campanelli C. Italia (2017) Gran Sala del Tribunal Europeo de Derechos Humanos.

71 Para una crítica más extensa al sesgo individualista de los razonamientos del Tribunal de Estrasburgo, Simón, (2017b).

72 Paradiso Campanelli C. Italia (2017) Gran Sala del Tribunal Europeo de Derechos Humanos.

73 AleXy (1986) pp. 295-296.

74 BERLin (2002) p. 171, citando a TAWNEY. 
clarecer la naturaleza de los derechos fundamentales, que se revelan como una realidad jurídica gracias a la acción de la razón natural que precisa su contenido, positivizándolo. Una proyección inmediata que nace de aquí es la reivindicación del valor de la función política y su institucionalidad, que sirve para encauzar el discurso racional cuando define el alcance de los derechos para una comunidad determinada. Otra consecuencia que se proyecta desde la determinatio es la necesidad de recalcular el valor de la sede judicial como instancia de protección de los derechos fundamentales. Esto podría disminuir el protagonismo político de los tribunales de justicia y, con ello, los riesgos que implica alejar a los jueces del ámbito propio del discurso judicial, donde prevalece la razón artifical del Derecho. Además de estas proyecciones en el orden institucional, se puede reconocer otra en el ámbito de la retórica de los derechos fundamentales. Porque la determinatio es una idea que presenta los derechos como realidades necesariamente limitadas, al asignarles la operación por la cual cobran entidad jurídica unos contornos y una finalidad específicos; en otras palabras, al descubrir los derechos fundamentales como una realidad teleológica. En último término, la determinatio tiene el potencial para sustentar una concepción de la libertad individual como un bien que solo es posible que se realice en un orden de libertades.

\section{BIBLIOGRAFÍA CITADA}

AleXY, Robert (1986): Theorie der Grundrechte (Francfort del Meno, Suhrkamp).

Aristóteles (1984): Metafisica, en The Complete Works of Aristotle (The Revised Oxford Translation, Jonathan Barnes (ed.), 2 Vols., Bollingen Series, Princeton University Press). Aristóteles (1984): Retorica, en The Complete Works of Aristotle (The Revised Oxford Translation, Jonathan Barnes (ed.), 2 vols., Bollingen Series, Princeton University Press). Aristoteles (1984): Etica Eudemia, en The Complete Works of Aristotle (The Revised OxfordTranslation, Jonathan Barnes (ed.), 2 Vols., Bollingen Series, Princeton University Press).

Atria, Fernando (2016): La Forma del Derecho (Madrid, Marcial Pons).

Atria, Fernando y Salgado, Constanza (2015): "El TC como tercera Cámara: la continuación de la política por otros medios", en El Mostrador, 9 de marzo de 2015. Disponible en: https://m.elmostrador.cl/noticias/opinion/2015/03/09/el-tc-como-tercera-camarala-continuacion-de-la-politica-por-otros-medios/ Fecha de consulta: 1 de noviembre de 2019.

BerLin, Isaiah (2002): “Two Concepts of Liberty”, en Liberty (Oxford, Oxford University Press).

Bilancia, Paola (2006): "Las nuevas fronteras de la protección multinivel de los derechos", Revista de derecho constitucional europeo, 6, pp. 255-277.

Bobbio, Norberto (1990): L'età dei diritti (Turín, Einaudi).

Contreras, Sebastián (2011): "Ley natural, determinatio y derecho positivo", Veritas, 25, pp. 39-54.

Corral, Hernán (2011): "Sobre la necesidad de los jueces y de las leyes. Una controversia entre Tomás Moro y Martín Lutero", en Carvajal, Patricio y Miglietta, Massimo 
(edits.), Estudios Jurídicos en Homenaje al Profesor Alejandro Guzmán Brito (Alessandria, Edizioni dell'Orso, Tomo II) pp. 69-126.

Dworkin, Ronald (1978): Taking Rights Seriously (Cambridge MA, Harvard University Press).

DwOrkin, Ronald (1981): “The Forum of Principle”, New York University Law Review, 56, Issues 2 and 3, pp. 469-518.

Coke, Edward (1628): The first part of the Institutes of the law of England, or, A commentary upon Littleton (Johnson and Warner and Samuel L. Fisher, Philadelphia, 1812, 3 Vol.)

Conwin, Edward (1928): "The 'Higher Law' Background of American Constitutional Law”, Harvard Law Review, Vol. XLII, No 2: pp. 149-185.

EsSER, Josef (1972): Vorverständnis und Methodenwahl in der Rechtsfindung (Francfort del Meno, Fischer Athenäum).

Favoreau, Louis Joseph (2001): "La constitucionalización del Derecho", Revista de Derecho (Valdivia), Vol. XII: pp. 31-43.

Finnis, John (1998): Aquinas: Moral, Political, and Legal Theory (Oxford, Oxford University Press).

FINNIS, John (2011c): "Human Rights and their Enforcement", en Collected Essays, III (Oxford, Oxford University Press), pp. 19-46.

FinNis, John (2011b): "Legal Reasoning as Practical Reason", en Collected Essays I (Oxford, Oxford University Press), pp. 212-230.

FinNis, John (2011a): Natural Law and Natural Rights (New York, Oxford University Press, second edition).

FinNis, John (2015): “Judicial Power: Past, Present and Future”, Lecture at Gray's Inn Hall, 20 October 2015, Oxford Legal Studies Research Paper No 2/2016. Disponible en: <http://dx.doi.org/10.2139/ssrn.2710880>. Fecha de consulta: 23 de noviembre de 2019.

Freixes, Teresa (2016): "Los derechos fundamentales: el enfoque multinivel", en T. FreiXes y J. C. Gavara (eds.), Repensar la Constitución: ideas para una reforma de la Constitución de 1978 (Madrid, BOE), pp. 23-38.

Fuller, Lon (2019): La Moral del Derecho, Fernando Contreras (trad.) (Santiago, Instituto de Estudios de la Sociedad).

García de Enterría, Eduardo (1963): "Reflexiones sobre la ley y los principios generales del Derecho en el Derecho administrativo", Revista de Administración Pública, número 40, Enero/Abril:pp. 189-222.

García de Enterría, Eduardo (1981): La Constitución como norma y el Tribunal Constitucional (Madrid, Civitas).

García de Enterría, Eduardo (2009): La lengua de los derechos. La formación del Derecho público europeo tras la Revolución Francesa (Madrid, Civitas, tercera edición).

García-Huidobro, Joaquín (1993): Razón práctica y iusnaturalismo (El iusnaturalismo de Tomás de Aquino) (Valparaíso, Edeval).

George, Robert (2000): "Kelsen and Aquinas on 'The Natural Law Doctrine", Notre Dame Law Review, 75-5: pp. 1625-1646.

Glendon, Mary Ann (1991): Rights Talk. The Impoverishment of Political Discourse (New York, The Free Press). 
Glendon, Mary Ann (2001): A World Made New. Eleanor Roosevelt and the Universal Declaration of Human Rights (Nueva York, Random House).

Hamilton, A., Madison, J., and Jay, J. (2005): The Federalist Papers (Indianapolis/Cambridge, Hackett Publishing).

Hegel, Georg (1820): Grundlinien der Philosophie des Rechts (F. Meiner, Gesammelte Werke, 14-1, 2009).

Henkin, Louis (1990): The Age of Rights (Nueva York, Columbia University Press).

Hirschl, Ran (2004): Towards Juristocracy (Cambridge, Harvard University Press).

JellineK, Georg (1921): Allgemeine Staatslehre (Berlin, Springer, $3^{a}$ ed.)

KäGI, Werner (1953): Hundert Jahre Schweizerische Recht, en Demokratie und Rechtssaat. Festgabe zum 60. Geburtstag von Zaccaria Giaccometti (Zürich, Polygraphischer Verlag A.G.).

KAnT, Immanuel (1968): Metaphysik der Sitten, Akademie-Ausgabe VI, Berlin. Disponible en: https://korpora.zim.uni-duisburg-essen.de/Kant/. Fecha de consulta: 31 de diciembre de 2018.

Kelsen, Hans (1929): "Wesen und Entwicklung der Staatsgerichtsbarkeit", en Veröffentlichungen der Vereinigung der Deutschen Staatsrechtslehrer, 5 (Berlin y Leipzig, Walter de Gruyter).

Kelsen, Hans (1949): "The Natural-Law Doctrine Before the Tribunal of Science", The Western Political Quarterly, Vol. 2, n. 4: pp. 485-486.

LeWIs, Clives Staples (2001): The Abolition of Man (New York, Harper Collins).

Lo, Chung-Shun (1948): "Human Rights in the Chinese Tradition" en Human Rights. Comments and Interpretations. A Symposium Edited by Unesco; UNESCO (Paris, pp. 185-189).

LOCKe, John (1690): Second Treatise of Government (Indianapolis y Cambridge, Hackett Publishing Co. 1980).

Maritain, Jacques (1948): "Introduction", en Human Rights. Comments and Interpretations. A Symposium Edited by Unesco; UNESCO, p. I.

Mill, John Stuart (1869): On Liberty (London: Longmans, Green, Reader and Dyer, 4th ed.). Disponible en https://en.wikisource.org/wiki/On_Liberty Fecha de consulta: 27 de noviembre de 2019.

Montesquieu (1748): Esprit des Lois, 4 tomos (a la librairie stéréotype, hue du pot-dt-feb, No 14, 1824). Disponible en: https://gallica.bnf.fr/ark:/12148/bpt6k9691133s. Fecha de consulta: 15 de junio de 2018.

Owen, Gwilym Ellis Lane (1960): "Logic and Metaphysics in some Earlier Works of Aristotle”, en I. Düring y G. E. L. Owen (eds.), Aristotle and Plato in the Mid-Fourth Century. Papers of the Symposium Aristotelicum held at Oxford in August 1957 (Göteborg, Almqvist \& Wiksell).

PuntambeKar S. V. (1948): Human Rights. Comments and Interpretations. A Symposium Edited by Unesco (Paris, UNESCO), pp. 197-201.

Rhonheimer, Martin (2011): The Perspective of Morality (Washington, Catholic University of America Press).

Rhonheimer, Martin (2013): The Common Good of Constitutional Democracy (Washington, CUA Press). 
Rubio, Francisco (2006): "Derechos fundamentales, derechos humanos y Estado de Derecho", Fundamentos, Núm. 4: pp. 203-233.

Simón, Fernando (2016): "La interpretación de los derechos en perspectiva teórica y práctica”, en F. Rubio Llorente y otros, La Constitución Política de España. Estudios en homenaje a Manuel Aragón Reyes (Madrid, Centro de Estudios Políticos y Constitucionales), pp. 895-918.

Simón, Fernando (2017a): Entre el deseo y la razón. Los derechos humanos en la encrucijada (Madrid, Centro de Estudios Políticos y Constitucionales).

Simón, Fernando (2017b): "Gestación subrogada o vientres de alquiler: reflexiones a la luz del Derecho comparado y de la jurisprudencia del Tribunal Europeo de Derechos $\mathrm{Hu}-$ manos”, en Revista General de Derecho Constitucional, 25: pp. 1-24.

Simón, Fernando (2018): "Subsidiarity, Human Rights and Judicial Activism: The Role of Courts”, en M. Dybowski and R. García Pérez (eds.), Globalization of Law. The Role of Human Rights (Cizur Menor, Thomson-Reuters Aranzadi), pp. 89-112.

STrauss, Leo (1953): Natural Right and History, (Chicago, University of Chicago Press).

StUart Mill, John (1875): Considerations on Representative Government (New York, Henry Holt and Company).

TAYLOR, Charles (1991): Ethics of Authenticity, (Cambridge, Harvard University Press).

TomÁs de Aquino, Scriptum super Sententiis, Textum Leoninum Romae 1888. Disponible en: http://www.corpusthomisticum.org. Fecha de consulta: 26 de julio de 2018.

Tomás de Aquino, Sententia libri ethicorum, Textum Leoninum Romae 1888. Disponible en: http://www.corpusthomisticum.org. Fecha de consulta: 26 de julio de 2018.

Tomás de Aquino, Summa Theologiae, Textum Leoninum Romae 1888. Disponible en: http://www.corpusthomisticum.org. Fecha de consulta: 26 de julio de 2018.

Waldron, Jeremy (1999): The Dignity of Legislation (Cambridge, Cambridge University Press).

Waldron, Jeremy (2001): Law and Disagreement (Nueva York, Oxford University Press).

Waldron, Jeremy (2006): "Principles of Legislation", en R. Bauman y T. Kahana (eds.) The Least Examined Branch. The Role of Legislatures in the Constitutional State (New York, Cambridge University Press), pp. 15-32.

Webber, Grégoire (2018): Legislated Rights (Cambridge, Cambridge University Press, Kindle Edition).

Whittington, Keith (2007): Political Foundations of Judicial Supremacy (Princeton, Princeton University Press).

Yowell, Paul (2018): Constitutional Rights and Constitutional Design: Moral and Empirical Reasoning in Judicial Review (Oxford, Hart Publishing, Kindle Edition).

\section{JURISPRUDENCIA CITADA}

Díaz Hernández con Fondo Nacional de Salud, Servicio de Salud de Concepción y MINISTERIO DE SALUD (2018): Corte Suprema, 6 de noviembre de 2018 (recurso de Protección), rol 17043-2018. 
Instituto Nacional de Derechos Humanos contra Servicio Electoral y Gendarmería DE Chile (2017): Corte Suprema, 2 de febrero de 2017 (recurso de protección), rol 87743-2017.

NN con Director General de Movilización Nacional (2003): Corte de Apelaciones de Santiago, 27 de mayo de 2003, (recurso de protección), rol 1970-2033.

NN CON Director General de Movilización NACional (2003): Corte Suprema, 25 de junio de 2003, (recurso de protección), rol 2270-2033.

Paradiso Campanelli C. Italia (2015): Tribunal Europeo de Derechos Humanos, 27 de enero de 2015.

Paradiso Campanelli c. Italia (2017), Gran Sala del Tribunal Europeo de Derechos Humanos. 24 de enero de 2017.

Sentencia 31/2018, (2018): Tribunal Constitucional de España, 10 de abril de 2018. 
